\title{
Coloquio Internacional AMAZONICAS III. Estructura de las lenguas amazónicas: fonología y sintaxis
}

Bogotá, 19-24 de abril de 2010

\section{Elsa Gómez}

\section{(2) OpenEdition}

\section{Journals}

Edición electrónica

URL: http://journals.openedition.org/bifea/2214

DOI: 10.4000/bifea.2214

ISSN: 2076-5827

\section{Editor}

Institut Français d'Études Andines

\section{Edición impresa}

Fecha de publicación: 1 abril 2010

Paginación: 217-218

ISSN: 0303-7495

\section{Referencia electrónica}

Elsa Gómez, «Coloquio Internacional AMAZONICAS III. Estructura de las lenguas amazónicas:

fonología y sintaxis», Bulletin de l'Institut français d'études andines [En línea], 39 (1) | 2010, Publicado el 01 octubre 2010, consultado el 02 marzo 2021. URL: http://journals.openedition.org/bifea/2214 ; DOI: https://doi.org/10.4000/bifea.2214

\section{$\Theta \Theta \Theta \Theta$}

Les contenus du Bulletin de l'Institut français d'études andines sont mis à disposition selon les termes de la licence Creative Commons Attribution - Pas d'Utilisation Commerciale - Pas de Modification 4.0 International. 
Évènements

\title{
COLOQUIO INTERNACIONAL AMAZONICAS III. ESTRUCTURA DE LAS LENGUAS AMAZÓNICAS: FONOLOGÍA Y SINTAXIS
}

\author{
Bogotá, 19-24 de abril de 2010
}

La tercera edición del coloquio internacional AMAZONICAS Estructura de las lenguas amazónicas: fonología y sintaxis tuvo lugar en la Universidad Nacional de Colombia de Bogotá, del 19 al 24 de abril de 2010. Fueron co organizadores del evento: la Universidad Nacional, la Universidad Vrije de Amsterdam, el Instituto Francés de Estudios Andinos (UMIFRE 17, CNRS-MAEE)y el proyecto francocolombiano ECOS-Nord C08H01. Contó también con el apoyo de la Embajada de Francia en Colombia.

Los dos primeros encuentros fueron organizados en el Brasil: Manaus en 2007 y Recife en 2008. Con AMAZONICAS III esta serie de coloquios se abre a todos los países del área amazónica para desempeñar un papel de semillero dentro de este conjunto regional, gracias a su periodicidad bienal y su carácter itinerante. Cada país - Venezuela, Colombia, el Ecuador, el Perú, Bolivia, el Brasil, Guayana Francesa, Surinam y Guyana- hospedará una de sus ediciones sucesivas. Perú fue el país elegido por los participantes a AMAZONICAS III para organizar en abril de 2012 el coloquio, AMAZONICAS IV.

El término AMAZONICAS remite a la riqueza lingüística de esta vasta región poblada

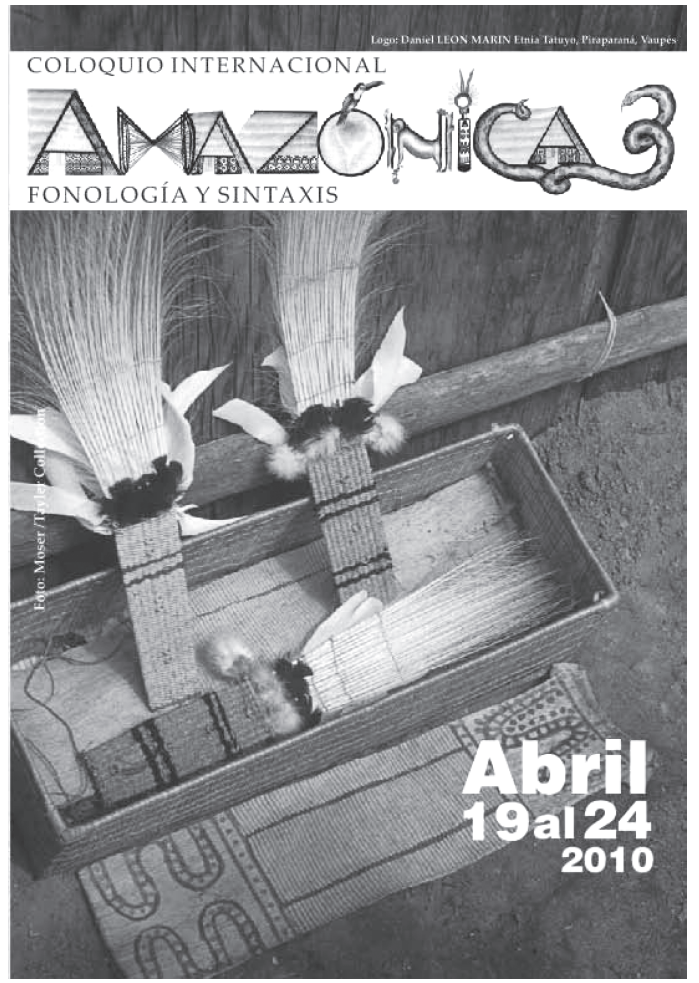
por gran número de pequeñas sociedades que conservan en alto grado formas de vida tradicional. Los temas tratados en estos encuentros cubren diferentes niveles de estructuración del lenguaje, pues las lenguas amazónicas están en vías de contribuir muy significativamente a la tipología tanto fonológica como gramatical. AMAZONICAS III constó de cinco simposios. Los temas de los simposios 1 y 2 -Fonética y fonología de rasgos laríngeos y Estrategias de aumento de valencia- fueron seleccionados por los participantes de AMAZONICAS II. Los simposios 3 y 4 -Expresión de nociones espaciales y Categorización léxica- forman parte de un proyecto ECOS-Nord de tipología fonológica y gramatical adelantado por lingüistas de la Universidad de Toulouse Le Mirail y de la Universidad Nacional de Colombia. Una novedad de este encuentro de Bogotá, representada por el simposio 5 - Lenguas arawak: estrategias de aumento de valencia- que deberá ser mantenida en encuentros ulteriores, consiste en reunir 
alrededor de un tema específico a los especialistas de una gran familia presente en el área amazónica.

A pesar de importantes cambios en la programación, causados por la ausencia de varios participantes europeos bloqueados por las cenizas volcánicas islandesas, el coloquio se desarrolló en un clima de entusiasmo e interés constantes, y promete la publicación de Actas muy enriquecedoras.

Gracias a esta serie de coloquios, los organizadores esperan dar, tanto a las lenguas amazónicas como a los investigadores que trabajan en la región, el puesto que les corresponde en el concierto mundial de ideas orientadas hacia una mejor comprensión de la naturaleza del lenguaje y de la diversidad de las lenguas.

Mayor información sobre los simposios está aún disponible en la liga: http://www. humanas.unal.edu.co/amazonicas3/ 